\title{
Women Coaches' Perceptions of Their Sport Organizations' Social Environment: Supporting Coaches' Psychological Needs?
}

\author{
Justine B. Allen and Sally Shaw \\ University of Otago
}

\begin{abstract}
Researchers have argued that coaches are performers in their own right and that their psychological needs should be considered (Giges, Petitpas, \& Vernacchia, 2004; Gould, Greenleaf, Guinan, \& Chung, 2002). The purpose of this research was to examine high performance women coaches' perceptions of their sport organizations' social context, with specific attention to psychological need support. Self-Determination Theory (Deci \& Ryan, 1985; Ryan \& Deci, 2002) was employed to frame the examination of the coaches' experiences. Eight high performance women coaches from two sport organizations participated in semistructured interviews. All reported autonomy and competence development opportunities. Organizational relatedness was critical to the experience of a supportive environment. The findings provide insight into the "world of coaching" from the coaches' perspective.
\end{abstract}

Coaches have been the focus of considerable research including examinations of coach behavior, athlete relationships (see reviews in Jowett \& Lavallee, 2007) and coach development pathways (Erickson, Côté, \& Fraser-Thomas, 2007). Such research typically aims to enhance the quality of athletes' experience by understanding their perspectives and ultimately influencing coaches' preparation for coaching and their interactions with athletes while coaching. However, researchers have also argued that coaches should be viewed as performers in their own right (Gould, Greenleaf, Guinan, \& Chung, 2002) and that coaches' psychological needs should be considered (Giges, Petitpas, \& Vernacchia, 2004). Furthermore, research has demonstrated that sport organizations' practices and culture influence coaches' experiences and effectiveness (Gould et al., 2002; West, Green, Brackenridge, \& Woodward, 2001). Consequently, research into the social contexts in which coaches operate is required to further our understanding of the support for their psychological needs. The general purpose of the present research was to examine high performance coaches' perceptions of their sport organizations' social environment and the extent to which their psychological needs are supported within this environment. In addition, the current study focused specifi- 
cally on the experiences of women high performance coaches. This emphasis on women was due to documented concern over the under-representation of women in coaching, particularly in high performance sport (Acosta \& Carpenter, 2008; Kilty, 2006; Shaw \& Hoeber, 2003),

In their recent manuscript Giges and colleagues (2004) pointed out that there is a large volume of sport psychology literature devoted to outlining suggestions for providing psychological services to athletes and that it is unfortunate that the needs of coaches have not been given the same attention. They argued that the needs of coaches are often neglected by sport psychologists as well as by coaches themselves. However, coaches are people, as are athletes, and have psychological needs that are critical for growth and well-being. This recognition of the needs of coaches provides an important juncture for sport psychology and coaching research. That is, rather than focusing on the coach because he or she influences athletes' sport experiences and performance, the coach is considered in his or her own right. As such, developing an understanding of the "world of coaching" (Giges et al., 2004) through the eyes of coaches becomes a legitimate pursuit, addressing a clear limitation of the current literature on coaching.

Gould and colleagues' (2002) research with U.S. Olympic athletes and coaches contributes to developing an understanding of the coaches' perspectives on coaching. They identified a wide range of factors that affected both athletes' and coaches' performance at two Olympic Games. The findings reaffirm the assertion that coaches are performers in their own right and that coaches' ability to perform their coaching duties in highly pressurized environments is important for athletes' effective performances. Of particular interest to the current study are the findings that coaches felt that operating in a positive environment was especially important for their effectiveness. Coaches characterized the positive environment as including having support from their sport governing organizations.

The relationship and experiences coaches have with their sport organization have also been identified in the, albeit limited, research examining women coaches' experiences. Theberge (1993) found that women coaches were marginalized and held a token status in which gender was highlighted through stressing physical differences between men and women and noting of the superiority of men's sporting experiences. Inglis, Danylchuck and Pastore (1996) identified three factors in their development of a work retention scale for coaching. These factors emphasized the social context within which coaches worked including organizational support, recognition of coaches contributions, and fostering collegial respect. West, Green, Brackenridge, and Woodward (2001) employed a model of occupational closure to analyze the experiences of 20 women coaches from a variety of sports. Their analysis revealed that strategies of exclusion and demarcation limited women's access to coaching roles. These included gendering the coaching role as a masculine one and closing access to networks of coaches. Despite this interest in the experiences of women coaches, to date there is limited understanding of the extent to which the social context coaches operate within, in particular the working relationship with the sporting organization, supports coaches' psychological needs.

A theoretical approach that has proven useful in furthering our understanding of people's psychological needs and well-being is Self-Determination Theory (SDT, Deci \& Ryan, 1985; Ryan \& Deci, 2002). SDT posits that the satisfaction 
of psychological needs is a necessary requirement for psychological health and that the social environment can support or thwart satisfaction of these needs. Three psychological needs are central to SDT. These are the need for autonomy, to feel the origin of one's behavior; the need for competence, to feel effective at one's dealings with the environment; and the need for relatedness, to feel connected with one's social world (Deci \& Ryan, 1985; Ryan \& Deci, 2002).

SDT has been employed to examine the characteristics of the social environment that support or thwart need satisfaction among workers (Gagné \& Deci, 2005) and athletes (Hollembeak \& Amorose, 2005; Mageau \& Vallerand, 2003; Reinboth, Duda, \& Ntoumanis, 2004) but not coaches. In their model of the coach-athlete relationship, Mageau and Vallerand (2003) applied tenets of SDT to propose that environments that are autonomy-supportive, provide structure and demonstrate involvement in athletes' welfare have direct influence on athletes' perceptions of their three basic psychological needs. Autonomy supportive behaviors included providing choice, rationale for tasks, opportunities for initiative taking and independence, avoiding controlling behaviors and acknowledging athletes' feelings and perspectives.

Research with athletes has demonstrated support for the tenets of SDT. Specifically, that athletes' perceptions of autonomy, competence and relatedness have been associated with positive sporting outcomes and are influenced by the actions of coaches (Hollembeak \& Amorose, 2005; Reinboth, Duda \& Ntoumanis, 2004). For example, Hollembeak and Amorose found that greater positive feedback from the coach was associated with athletes' perceived relatedness, while democratic coaching behaviors were associated with greater perceived autonomy. Reinboth and colleagues found that male adolescent athletes who perceived greater coach social support were more likely to report greater perceived relatedness.

The concept of need satisfaction has also proven to be useful in examinations of work organizations' social context. It provides a basis for delineating aspects of the social context that will support self-determined motivation and related positive outcomes. Furthermore, those in leadership positions are a crucial part of the social environment and therefore have an important role to play in supporting or thwarting need satisfaction. Research in the workplace has provided support for the SDT approach to understanding work motivation (see Gagné \& Deci, 2005 for a review). Gagné and Deci's review revealed that a work climate characterized by managerial support for employees' autonomy was related to the satisfaction of needs for autonomy, competence, and relatedness. Managerial autonomy support includes acknowledging subordinates' perspectives, offering choice, and encouraging self-initiation. Gagné \& Deci (2005) focused on autonomy supportive management in the for-profit sector, however, similar findings have been demonstrated with volunteer workers. For example, in two studies, one with college students and one with volunteer workers, Gagné (2003) found that autonomy support was positively related to need satisfaction.

SDT has proven useful in furthering our understanding of how coaching behaviors and the coach-created social environment influence athletes' basic psychological needs and motivation. It has also proven to be useful in delineating aspects of the social environment in the workplace, for both paid employees and volunteers, that influence need satisfaction. Therefore, SDT appears to be a viable 
framework for examining the social environment in which coaches operate and the extent to which sport organizations support coaches' psychological needs.

Researchers examining women in coaching in the USA have discovered that as pressure to succeed at the highest levels of sport impacts on funding, men are more likely to be employed in coaching roles over women, despite some women's greater experience in the sport concerned (Acosta \& Carpenter, 2008). In part, this discrimination may occur because gendered assumptions by organizational members ensure that women are considered to be less "natural" coaches, particularly at the higher levels (Kilty, 2006; Shaw \& Hoeber, 2003). The under-representation of women in coaching roles in New Zealand, where the current study was conducted, is clearly illustrated in some recent data from New Zealand's Olympic and Commonwealth Games teams. At the 2006 Commonwealth Games in Melbourne, Australian, New Zealand women were under-represented in coaching roles relative to the number of women athletes. Of the 48 coaches, from 18 sports, only 14 $(30 \%)$ were women compared with almost half of the 249 athletes (NZ Olympic Committee, 2006). Furthermore, at the 2008 Olympics in Beijing, China only 3 (7\%) of the 43 coaches were women compared with $46.7 \%$ of the competing athletes (NZ Olympic Committee, 2008). These figures are comparable with those documented in the United Kingdom where women accounted for only $10 \%$ of Great Britain coaches at the 2004 Olympics compared with 39\% of athletes (Women Sport Foundation, 2007) and in 2000 in Canada where only $11 \%$ of national teams were coached by women (Marshall, 2001).

Relatively little sport psychology research has explicitly examined women coaches' experiences. Recently, Kilty (2006) described a number of external and internal barriers to professional opportunities reported by elite level women coaches attending a conference on women in coaching. The social context of the organization such as lack of female mentors, unequal assumptions of competence, and balancing work and personal life were common reported barriers. However, little is known about the extent to which the social context influences women coaches' psychological needs. Therefore, the purpose of the present research was to examine women high performance coaches' perceptions of their organizational social environment using SDT (Deci \& Ryan, 1985; Ryan \& Deci, 2002) with specific attention to the support for psychological needs.

\section{Method}

\section{Participants}

The participants were eight women high performance coaches from two Regional Sports Organizations (RSOs) in one region of New Zealand. The coaches ranged in age from 27 to 54 years $(M=40.1$ years). Their total years of coaching experience ranged from 7 to 17 years $(M=12.4$ years). All participants had completed at least Level 2 of a national three-level coaching qualification program in their sport. Seven of the coaches had also attended additional coach education opportunities such as conferences, short courses, and seminars. Only one of the eight coaches was employed as a coach, the other seven were volunteer coaches. Five of the volunteer coaches were employed in secondary or tertiary education. 


\section{Procedure}

Two organizations were purposively selected because of their differences in numbers and retention of women coaches. One organization represented a popular sport played predominantly by women and had large numbers of women coaches (Organization A). In contrast, the second organization represented a popular sport played by both women and men and had small numbers of women coaches (Organization B). Purposive criterion sampling was used to identify potential participants for the study (Patton, 2002). Female high performance coaches who were either coaching or had coached at the regional under 18/19 years, under 21 years, or Open level in the last three years were identified via their Regional Sport Organization (RSO) and invited to participate in the study. High performance coaches were chosen because it is when women begin to compete for coaching jobs at representative or professional levels that their numbers dwindle (Acosta \& Carpenter, 2008; Shaw \& Hoeber, 2003). Four coaches from Organization A were invited to participate in the study. In Organization B there were only three women high performance coaches. They were all invited to participate. A fourth coach in Organization B who had retired from coaching a year before data collection was also invited for interview, due to her long-term, high performance coaching experience. All eight coaches agreed to participate in the study.

Interviews were conducted at a location of the participants' choice and lasted approximately $60 \mathrm{~min}$. In keeping with our university's ethical procedures regarding confidentiality, the organizations are not named but are referred to as Organization A and B. All participants were given a pseudonym that identifies them as belonging to Organization A or B and a number (e.g., OrgA \#1 or OrgB \#3).

\section{Data Collection}

Interviews were conducted to examine the day-to-day experiences of female high performance coaches through an analysis of their perceptions of the sport organization social context and their relationship with the RSO. Interviews were semistructured to provide rich, thick description of the coaches' experiences (Burgess, 1982; Fontana \& Frey, 2000). In keeping with semistructured interview and qualitative protocol, the interviews were conversational in nature. This process allows rapport to be developed between the interviewer and participant and supports the expression of the participant's point of view (Burgess, 1982). The interview occurs within a framework of topics to be discussed and the specific questions and probes may vary with the flow of the conversation (Burgess, 1982; Fontana \& Frey, 2000). As such, the interview questions were designed to encourage the coaches to describe their experiences within their RSO. An interview guide was developed based on SDT concepts, specifically focusing on aspects of the social context that supported coaches' autonomy, competence, and relatedness. Questions included "What kind of involvement does the organization have in your coaching?"; "What development opportunities have been provided by the organization for your coaching?" and "How would you describe your relationship with other coaches?" Both researchers made brief research notes about the participants' comments, which could be used as a back up to the audio recordings, and also to substantiate the transcripts (Burgess, 1982). 


\section{Data Analysis}

The interviews were audio tape recorded and transcribed in full. Transcripts were offered to all participants for review and to provide additional comments. All participants declined this offer indicating that they had ample opportunity to express their views within the initial interview. To provide some triangulation of the data the transcripts were then compared with the research notes for consistency (Janesick, 2000).

Due to the clear theoretical basis of this study a deductive analysis process was employed using SDT as the framework (Patton, 2002). The coaches' experiences were initially organized under the existing thematic concepts of autonomy, competence, and relatedness. Within each of these themes an inductive process was used to develop subthemes which provided the opportunity to examine the detail of the data.

The transcripts were manually coded independently by both researchers. We followed Silverman's (2001) suggestion to accept interviewees' accounts as full and accurate description of their own experiences. However, to ensure consistency in our interpretations of the data and in keeping with our desire to analyze women coaches' experiences through their articulations of perceptions of the organizational social environment, both authors examined the data for commonalities, contrasts and tensions (Janesick, 2000). The researchers then compared results, discussing similarities, overlap, and redundancy in the data where necessary.

\section{Results}

Using the concept of support for the psychological needs the data are presented under three themes. These themes are organizational support for coaching autonomy, coaching competence development opportunities, and sense of coaching relatedness. Each theme contained several sub themes which are presented with illustrative quotes. Similarities and differences are identified between the experiences of coaches working in Organization A and those working in Organization B.

\section{Organizational Support for Coaching Autonomy}

All coaches indicated that they were able to work independently from their organization in their coaching practice with athletes. As one coach from Organization A put it "I mean it's up to me to coach how I want to coach . . . they [Org A] are basically 'you do your program. You set your program' and give it to them" (OrgA \#4). Another Organization A coach said "in terms of our planning and the way the team runs they [Org A] don't have any involvement" (OrgA \#3). One Organization B coach commented "once you get your time you know your [practice] bookings, you just go on doing your thing" (OrgB \#2). Another coach summed up the independence from the organization by saying "Here's your balls and cones, so you know, see you later" (OrgB \#3). All the coaches had independence with regard to their work with athletes and therefore can be described as having autonomy in their coaching. However, the extent to which coaches felt their independence was supported by their organization or merely their only option was strikingly differ- 
ent between the two organizations. These differences were demonstrated through the actions of the organizations and presented in three sub themes: guidelines and assistance for tasks; acknowledging individual needs; and opportunities for input to the organization.

Guidelines and Assistance. The experiences of the coaches from the two organizations were markedly different with regard to administrative tasks related to coaching, such as finances and travel arrangements. Providing guidelines and assistance may not seem consistent with supporting autonomy. However, this level of involvement with the coaches' day-to-day activities demonstrated an effort by the organization to recognize the coaches' perspectives and take an interest in the coaches' work which the coaches appreciated. Organization A took responsibility for many of these tasks. One coach described the organization's role in her coaching administrative tasks "in terms of organization and going away on trips and all the bits and pieces that goes with that they're really proactive" (OrgA \#3). Another coach explained the existence of processes to guide coaches but not interfere with their actual coaching:

I mean there's a guideline as far as financial. . . you do your budget with your manager and give it to them and they approve it. So I guess from that you know you're on the right track you know you can't step out of line, I mean you can't do things that they're not OK with (OrgA \#4).

One coach in Organization A did feel that the limits needed to be clearer and assistance from the organization more proactive. She talked about:

. . . frustrations last year when I put a budget in and asked for competition games . . . they said yes and then two weeks before we were supposed to go on one of the trips they said 'No you can't go, there's no money' . . . If they'd said no to me in November I could've planned for it (OrgA \#1).

In contrast, Organization B coaches reported experiencing a complete lack of assistance or guidelines. The coaches were responsible for every aspect of their coaching including administrative tasks. When asked about the organization's assistance one coach replied that it was "non existent." Another described the situation in more detail:

You organize how you're getting up to [away venue] for the weekend or you just sort of do everything yourself . . . making sure the transport's right, the food's right, the accommodation all that side of it . . . every single thing you were just totally organizing yourself. ... They [Org B] don't sit down one-onone with the coaches, ok, what can we book for you (OrgB \#2).

Individual Needs. As with assistance and guidelines, only the coaches in Organization A felt that the organization worked to acknowledge coaches' individual needs. For example, one coach said "they [Org A] recognize that the coaches are all individuals and have their own strengths too . . . if I need any help with anything I would go through [Org A]" (OrgA \#4). Another coach explained the organization's support for her family commitments: 
[My son] is 11 months. . . . He came with me to [tournament] and [Org A] were fantastic they funded a friend of mine to come and look after him. So when I was coaching that's all I was doing, not trying to juggle the two.... I mean they made it possible for me to go ... I couldn't have left him behind and I couldn't have coached with him if I just had him, nobody to look after him. ... they are family friendly (OrgA \#3).

Input to Organization. Another feature of the social context was the opportunity for input to the organization. Both organizations had a debriefing with groups of coaches at the end of the season where the coaches were able to feed back to the organization. The coaches appreciated this opportunity. One coach described the process in this way "we do evaluations, we actually fill in an evaluation form um you know what went well, what could we do better. We actually usually have a coaches get together at the end of the year where we discuss that" (OrgA \#4). A coach from Organization B explained their similar process but felt that the feedback was not taken on board by the organization.

Despite these feedback processes, the coaches did not feel that they had significant input into the organization as the discussions tended to revolve around administrative aspects of their coaching such as quality of accommodation. For example, one coach called it the "little stuff". Several of the coaches felt that they had more to offer their organizations but there was no avenue to present their ideas or little changed as a result. A coach from Organization B said "it's a shame because I've got things to offer other people, but there's nowhere really for me to" (OrgB \#2). A coach from Organization A described her frustrations "they've, you know, maybe listened but still haven't, hasn't made a difference” (Org A \#1).

\section{Coaching Competence Development Opportunities}

The coaches reported the actions of their organizations that influenced the range of opportunities available to develop their coaching competence. These were organized in to three sub themes: opportunities and support for formal training and preparation; feedback and mentoring support; and constraints to development and assistance.

Opportunities and Support for Formal Training and Preparation. Coaches from Organization A were generally happy with the formal opportunities for competence development available to them. They identified formalized coaching pathways to train and prepare them for coaching. For the coaches in Organization A these opportunities were clearly set out by their sport's national governing body "[National Governing Body] have quite a career path in terms of your accreditation" (OrgA \#2). They felt that there were a lot of formal education opportunities available to them and they recognized the importance of the courses for their development as high performance coaches. As one coach stated "I thought well if I'm going to coach at a higher level I need to put myself out there, attend more of these courses, which there is heaps available" (OrgA \#4).

The opportunities available to the coaches in Organization A included sport specific level 1, 2, \& 3 coaching courses and practical opportunities. Despite some initial hesitancy from several coaches about the value of the courses, all the 
coaches felt that they were good opportunities to learn. One coach explained her thoughts on the courses, "Some of the earlier courses were probably, 'I know all this stuff anyway'... sometimes its just to reaffirm what you know and do. ... I've enjoyed all of them and there's been something I've taken out of all of them" (OrgA 1). Another coach stated that:

I was really anti that [the courses] for a start, I remember thinking I don't need to go and um be told how to coach and that's not going to make me a better coach and I don't need that. And then once I got over that I thought yeah ... it was another tool to use in your coaching . . . Because when you do those levels ... you certainly learn from other coaches and pick up things the whole time (OrgA \#4).

Formalized practical opportunities were also highly valued by the coaches. These included involvement in national training camps and the NGO's apprentice coach initiative. Such initiatives provided the opportunity to observe and work with other high performance coaches. One coach described her involvement as "a really good experience because you worked with other elite coaches and I learnt a lot from that" (OrgA \#4). Three of the coaches had been through the NGO's apprentice coach initiative where they were part of team but had no coaching responsibilities. Each of the coaches had high praise for the scheme. For example:

You were aligned to a provincial team . . . during the period of the 10 weeks or so you're involved, [NGO] had tasks that you did. . . . (A)nd over the two weeks of nationals, all the apprentice coaches were together, and we would analyze the games. We weren't aligned, at that stage with our team as much. We could go off to the side together, watch games all day and we would be in theory groups. It was really interesting. . . . It [game] might be videoed and then we'd come back and [they'd] say well what did [you] observe. (OrgA \#2)

[You] don't have any responsibility and it was good especially at that time when I was wanting more confidence, just to be able to sit back and observe really. Because you don't [usually] get a chance to work with other coaches because you're too busy doing your own thing. (OrgA \#4)

Two of the coaches in Organization A recognized the support of the organization, particularly from the coach development officer, in fostering the development of coaches' competence. This was achieved through provision of information, organizing seminars, and general encouragement. One coach said, "The development officer, she's always been a real encourager. She's always out there trying to get coaches to, to get you know their accreditation and everything" (OrgA \#2).

In contrast, the coaches from Organization B were not satisfied with their competence development experiences. The formal education opportunities that were available to the coaches were valued. One coach said, "That level 2 [course] I went to, there were coaches from all around New Zealand and I found that was so beneficial, I learnt so much there off other coaches" (OrgB \#2). However, the 
coach pathway was less clear, the formal education opportunities were much less readily available, and there was a lack of support from the organization. One coach described her experiences this way "there is no pathway. No. For me there hasn't been a pathway...I had to argue so hard, was it that I might be old, might be female, but I am still developing, and I am prepared to put the work into develop as a coach and I had to argue so hard [for opportunities]" (OrgB \#1). Another coach related her experiences:

It's quite limited and I feel the [organization] should be doing more to up skill coaches. Cause you sort of feel that you get to a level that you're not really developing. ... There's nobody really to take you to the next step. There's no interest either in taking coaches to the next step. (OrgB \#2)

This coach went on to describe how she felt she had no choice but to find her own opportunities:

I soon learned I wasn't gonna get much from anywhere else here, you know what top coaches do, . . . so I'd be at tournaments, I'd be watching teams warm-up, you know when my team wasn't playing and watch teams that were playing really well and seeing what their coaches were doing ... so I just kept up skilling myself, with books and talking to other coaches and going watching maybe [top coaches in other sports] . . . I just did things myself, off my own back basically. (OrgB \#2)

Feedback and Mentoring Opportunities. All the coaches expressed a desire for feedback so that they could continue to develop their coaching competence. As one coach stated "I just think you can't get better if you don't get the feedback" (OrgA \#1). The coaches recognized that feedback from a variety of sources was useful such as from athletes, other coaches including mentors, and the organization. Several of the coaches in both organizations solicited feedback from their athletes which they valued. A coach from Organization A explained an end of season feedback process, "The players do an evaluation, we talk about what they've said could be better ... what they thought of all parts of the season" (OrgA \#4). A coach from Organization B explained her use of athlete feedback:

I do a lot of surveys with the [athletes], what do you like about my coaching, what don't you like about my coaching, it's all anonymous, what do you like about the warm-ups, what do you like about the game plan, our team talks, so they're constantly evaluating me and I'm constantly getting feedback for the level that I'm at. (OrgB \#2)

All the coaches talked about the importance of gaining feedback from other coaches. However, only the coaches in Organization A had networks among the coaches where this actually happened. One coach described her experience:

Often [experienced coach] would come and watch my girls play then we'd talk about it afterwards. And I'd say I thought so and so was doing this wrong or did this really well and she would then bounce other ideas off me as well. 
It's great to have more feedback than just your own. . . . I wouldn't be without her. I couldn't do it on my own. (OrgA \#3)

The Organization B coaches were looking for experienced coaches to help them develop further but did not feel that the opportunities were available. One coach explained "I always feel like [the experienced coaches] are a bit bored, wanting to talk about themselves, but not wanting to sort of say, "what did work, what system did you use?" (OrgB \#1). Another coach felt that because she had been successful "there weren't a lot of people that would feel comfortable or would come and evaluate me because they would think, oh, you know, I don't feel comfortable telling her what to do" (OrgB \#2).

All the coaches in this study mentioned that a mentor would be useful for their development, however, neither sport had a formalized mentoring system in place. Of the Organization A coaches, only one had a mentor. She had approached the mentor herself and valued the contribution this person had in her development. "I've instigated my own mentor ... she's fantastic and she'll come to trainings and give me feedback or you know, she's available to talk at any stage so like, I found that really extremely valuable" (OrgA \#1).

Another coach highlighted an important difference she had experienced between feedback through a more informal mentoring type relationship and formal assessment feedback:

[It was] completely different, [the mentor-type coach] was great in terms of I knew my neck wasn't on the line and I wasn't going to fail you know. . . . I probably learnt more from that half a day with [the mentor-type coach] than I did from an assessment, just because assessment was just telling me the basics of structuring and running a training and that type of thing. Whereas [the mentor-type coach] was more thinking about the game and knowing how it happens in that one hour of playing, opposed to preparing for the one hour of playing (OrgA \#3).

None of the Organization B coaches had mentors but all expressed a desire for greater connection with other coaches and particularly with more experienced coaches. One coach expressed it this way "I see people like myself should be maybe buddied up with an [elite] coach, like, the next level up. And just as a mentor type, that would be quite helpful I think" (OrgB \#3). Another said "a mentoring type system. Some more mature coaches would come and be with a representative coach and watch them, or at least watch them once in a while" (OrgB \#1).

Another source of feedback the coaches felt was important for their competence development as high performance coaches was feedback from their organizations. Coaches from both sports felt that their organizations could do more to foster their competence through direct feedback about their coaching and through taking a more proactive role in their development. One coach described her experience in this way:

I've had nothing back from the [organization]. . . . I mean they've been supportive of me, in any face to face contact . . . but I question whether they had enough involvement to actually to know if I was doing a good job of coaching ... I've instigated it [development opportunities] as opposed to someone 
taking me aside and saying it would be a good idea for you to do this . . . mostly it's come from me. I've approached them and said that I wanted to go to courses. (OrgA \#1)

The lack of proactivity from the organization was raised by two coaches. One said "No, I wouldn't say I was groomed [laughing] . . . more like we haven't got a coach would you be interested?" (OrgA \#2). Another commented, "I do question how proactive some of them [Org A] were . . . there doesn't appear to be a succession plan of coaching ... no grooming of people to try and take over" (OrgA \#1).

The coaches in Organization B had similar experiences of a lack of feedback or planning from their organization. They expressed this with the following comments "I mean the present organization you don't really get feedback not about you. Who is going to come and bother?" (OrgB \#1). Another said "they don't really do much for the coaches. As long as they've got somebody in that slot taking a team, they're not really too worried . . . nobody ever really came and evaluated me" (OrgB \#2). A third coach had a similar experience "nobody said anything to me during the season, except when we won a game, I gave the equipment back months ago and have heard absolutely nothing since" (OrgB \#4).

Constraints to Development and Assistance. Despite being generally happy with their formal education opportunities when they were available, the coaches also identified several constraints to their competence development. These included financial constraints, having to be selected or invited and gendered assumption about competence. A coach from Organization B identified organization finances as a constraint to coach development opportunities: "They've got to find money to keep up-skilling not only their men, you know both male and female, I suggested why not get people [elite coaches] here, but it was in the too hard basket" (OrgB \#2). Selection or invitation to attend courses and having to be 'pushy' was also a barrier to development. One coach expressed it this way: "It seems to be you have to be a certain level to get invited" (OrgA \#2). All of the Organization B coaches felt that they had to be assertive or 'pushy' to get action from the organization. One coach stated that "the level 2 [course] was good. I fought incredibly hard to get into that" (OrgB \#1). Two of the coaches from Organization B felt that not getting the opportunity to coach higher teams was a constraint to their development as a coach. They felt this lack of opportunity occurred because male coaches were considered better even if they were less well qualified. For example, one coach explained her experience:

I mean I know I'm as good as these guys ... how much do I have to do to prove ... it was really a gender thing ... I have everything the same as [the male coach] who is currently coaching [the open team] apart from the fact he hasn't got his level 2 [accreditation]. Perhaps I should have a gender change (OrgB \#1).

Only the coaches in Organization A identified assistance from their organization in negotiating constraints to their development as coaches. This assistance included a supportive attitude to family commitments and financial support to attend courses. One coach described the attitude to family: "They are very very supportive. . . . Like some of the courses I've been to there's babies there and ... 
it seems to be absolutely fine to do that" (OrgA \#4). She also commented on the financial assistance provided by the organization "when I suggested I go and they've [Organization A] paid for the entry to it and the cost of the course" (OrgA \#4). In contrast, Organization B coaches did not report any assistance with constraints to competence development. In fact with regard to financial assistance one coach described this situation "I said to [CEO], who pays for that level 1 [course] if they were to do it. "They have to pay themselves" (OrgB \#1).

\section{Sense of Coaching Relatedness}

Most of the coaches indicated that coaching could be a somewhat isolated existence. A coach from Organization A expressed it this way "I mean in the end coaching can be pretty lonely" (OrgA \#1). Two of Organization B's coaches made these comments "I mean the isolation is unbelievable really" (OrgB \#1); "you're pretty much, I felt, there on your own" (OrgB \#2). The importance and benefits of developing a sense of relatedness were captured through three sub themes: connections among coaches, barriers to connecting with coaches, and connections with organization.

Connections Among Coaches. The connection with other coaches was valued by all coaches. Organization A coaches had a clear sense of relatedness with other coaches in their sport and recognized that this provided them with support, feedback, and different perspectives. This was reflected in the following comments from the coaches: "Once you get your networks going . . . we worked reasonably closely together, you talk about a game and then we'll go away and have a coffee and talk about what we thought about the teams" (OrgA \#3). Another coach discussed how important the relationships were to her:

There's other coaches that I sort of use and I think that's probably really important ... that we can go to each other and talk about things . . . a lot of it's just spur of the moment it's just you finishing training together you know you go and find the other coach and just say I need to talk to you for a minute ... [when things weren't going well] it was actually nice to have those other coaches that you can shut the door and kick the wall, without it involving the players. ... I think that the good part is that when the chips are down they are there for you as well. (OrgA \#4)

In contrast, Organization B coaches did not have the same sense of relatedness with other coaches in their sport. One coach described the connection between coaches as "pretty non-existent" and said that "I'd see people at the [sport venue] I wouldn't really know who they were or what team they were coaching, it's pretty terrible really" (OrgB \#2). Another coach suggested a similar lack of knowledge of the other coaches "I couldn't probably name half of the coaches" (OrgB \#3). They did however, all express interest in developing networks among the coaches in their organization and recognized potential benefits such as supporting one another and sharing ideas. One coach explained her desire for coaches to have a support person: 
I would like to see, probably each of those rep coaches have somebody . . . who they can talk to afterwards and have a debrief really. . . . I've noticed people are quite isolated ... you are so on your own. . . I I have absolutely no body to talk to about it. (OrgB \#1)

Another coach described the desire to share ideas:

I would have loved it . . . if I could have gone along to a coaches club, and have an [elite] male and female coach talking about how to select a team or all the things that you actually need to know, and you can take everybody's [ideas] and ... take a bit from everybody. (OrgB \#2)

Barriers to Connecting With Coaches. Coaches from both organizations identified several barriers to developing useful relationships among coaches. These included time, difficulty breaking into existing networks, and competition with each other for positions. The idea of competition was expressed by three coaches. For example one coach said "I think there's almost like a distrust of other people. I can't share that with them cos they might get better than me or, you know?" (OrgA \#1). Another described it this way "it's all so competitive, . . . as coaches we all know each other, and go on the booze and do all those things, and then on the other hand we are all competing at a certain level for certain positions" (OrgA \#2). A third explained "two of us were neck and neck in terms of who to have and he [CEO] was saying, give me reasons why we should have you rather than [her]. Only I didn't want to compete with [her]" (OrgB \#1).

Connections With Organization. In addition to developing relationships with other coaches, the sense of connection with the organization was also important to these coaches. This connection included feeling that the organization was involved with the coaches' work and that their efforts were recognized and valued. In Organization A two coaches noted their appreciation of the organization's involvement. One of these coaches described the relationship in this way:

I think it just basically knowing that they are there for you, if you need the help they certainly will help you ... [CEO] pops in from time to time . . . they're always asking how it's going, is everything $\mathrm{OK}$, is there anything that you need, you know, we want to help you. (OrgA \#4)

However, two coaches did not think this level of involvement was enough. One said:

I tried to involve, you know they [Organization administrators] were welcome to come to trainings, I went to Board meetings last year but I got sick of it cos it was like you'd turn up and half the people weren't there or they'd be cancelled at the last minute ... it's just there's no support. (OrgA \#1)

For Organization B coaches the relationship with the organization was far from satisfactory. One coach expressed her feelings in this way "I mean I don't know if the organization would even care if I wasn't there" (OrgB \#1). Another described her disappointment in the level of involvement from the organization with reference to an specific situation: 
Like it's always nice to feel as though someone's watching out for you and seeing how you're getting on ... . when we're away at tournament and we never got one piece of communication from anyone to do with [the organization] about how we were going. (OrgB \#3)

The coaches' suggestions for what they would like from Organization B provided further evidence of a lack of satisfaction with their relationship. For example, one coach suggested that "just a general support, not specific. Not do this, do that ... but just maybe an introductory talk. Maybe [the CEO] could come in and just say hi to the team and that they are backing you" (OrgB \#1).

With regard to organizations recognizing coaches' efforts and demonstrating that they were valued, two coaches expressly stated that they did not seek recognition. One commented "you're probably not in it for the recognition its personal satisfaction" (OrgB \#2). However, the remaining coaches felt that it was important coaches' efforts were recognized and that they felt valued. Several small measures were in place to provide this recognition. For example Organization A sent out thank you letters, gave teams send off parties before leaving for their tournaments while Organization B had an end of season function for the coaches. However, several of the coaches felt more needed to be done. One coach made these suggestions:

I think making sure people feel valued is huge. . . . I think just recognizing and thanking people is huge. . . . Coaches often don't get thanked. . . . I just think recognizing the time that they give up . . . and just support that you're there if you need someone to talk to, but I think definitely a thank you is huge. (OrgA \#1)

A coach from Organization B suggested:

I always loved being able to debrief. I mean it makes you feel somebody cares, if you can talk about issues and problems even if they are just pretending to care ... most people would give up after a year um because the lack of value, feeling your ideas have not been noticed. (Org B \#1).

\section{Summary}

Organization A coaches appeared to operate in a largely autonomy-supportive social context. Their independence and initiative were encouraged within clear guidelines, there where high quality training and preparation opportunities, and they felt a sense of connection with other coaches and the organization. In contrast, Organization B coaches appeared to operate in a largely laissez-faire social context where they had independence but there were little or no guidelines, there was a lack of competence development opportunities or support for this, a perceived lack of involvement and value from the organization and little or no connection with other coaches. 


\section{Discussion}

The under-representation of women in high performance coaching has been welldocumented (e.g., Acosta \& Carpenter, 2008; Marshall, 2001; West et al., 2001). In addition to documenting the status of women in coaching, researchers have frequently focused on describing barriers that women face (e.g., Doherty \& Casey, 1996; Kilty, 2006). The purpose of this study was to examine women high performance coaches' perceptions of the social context within their sport organization with specific attention to support for their psychological needs. The findings provide support for the use of Self Determination Theory (Deci \& Ryan, 1985; Ryan $\&$ Deci, 2002) to frame the examination of psychological need support for coaches within an organizational setting. All the coaches experienced a sense of autonomy and competence in their coaching and some felt a sense of relatedness with other coaches and their organization. However, the extent to which their social environment was experienced as supportive of their psychological needs varied among coaches and between organizations. This variation was largely due to the extent to which coaches felt a sense of relatedness with coaches and key personnel in their organization. The current research therefore, contributes to the literature in three ways: (1) extending the SDT concept of autonomy-supportive environments to the 'world of coaches'; (2) identifying aspects of the social context that are important to the psychological needs of women high performance coaches; (3) emphasizing the importance of relatedness among coaches and key organization personnel.

Gagné (2003) described autonomy supportive contexts as "giving people choice and encouragement for personal initiative and also support for people's competence in a climate of relatedness" (p. 203). The features of the social context the coaches in the current study identified were consistent with previous research examining athletes' and workers' (paid and voluntary) perceptions of their social contexts (Gagné \& Deci, 2005; Hollembeak \& Amorose, 2005; Mageau \& Vallerand, 2003; Reinboth. et al., 2004). These included autonomysupportive actions by their organizations that were present to greater or lesser degree such as independent work and initiative opportunities, guidelines, training opportunities, assistance with constraints to development, feedback, acknowledging individual perspectives, regular involvement and interest.

A feature of the social environment that appeared critical to the experiences of the women coaches in the current study was the coaches' sense of relatedness. Ryan and Deci (2002) have described the need for relatedness as a fundamental human need that reflects a need for "feeling connected to others, to caring for and being cared for by those others, to having a sense of belongingness with other individuals and with one's community" (p. 7). All the coaches desired this feeling of 'being connected' with others in their organization ('individuals' and 'community'). However, only the coaches in Organization A felt this connection. Actions by the other coaches and key personnel in Organization A supported the coaches' activities and assisted with their development not only satisfied the needs for autonomy and competence but crucially demonstrated an interest and involvement with the coaches as people as well as in their work. One example of this consideration for the individual was the assistance that was provided in relation to 
family commitments. The challenge of balancing coaching and family commitments has been identified as a barrier to women coaches' progression (Kilty, 2006). The demonstrated concern for the individual and recognition of their efforts that contributed to the coaches' sense of relatedness. In contrast, for Organization B coaches the lack of interest and involvement from others in their organization led to a feeling that 'no one cared'. This resulted in feeling that they had to operate autonomously rather than feeling supported, feeling little support for their competence and little satisfaction of their need for relatedness.

Gagné (2003) described autonomy supportive contexts as operating within a 'climate of relatedness'. The findings from the current study suggest that the relationships coaches have with significant people in their working environment such as other coaches and key organization personnel are critical to their experiences. Furthermore, these relationships could even influence the extent to which the coaches feel they are experiencing support for all three of their psychological needs. That is, developing quality connections within an organization may be at the heart of developing an autonomy-supportive social context rather than an 'added extra'. The desire for a working environment in which individuals feel supported by their organization is consistent with Gould and colleagues' findings with Olympic Games coaches (Gould, et al., 2002). This perspective also provides support for Kilty's (2006) recommendations regarding the importance of developing inclusive work environments and an emphasis on relational work cultures for women coaches.

The quality of the connection with the organization can also be supported by research in work settings. Gagné and Deci (2005) suggested distinguishing between job content and work climate in examining aspects of the social context that influence need satisfaction. The main feature of the work climate was the relationship between managers and workers conveyed through autonomy supportive actions. In their analysis the relationship was separated from characteristics of the job itself such as whether there is choice, challenge and feedback present. Again this illustrates a distinction between having autonomy due to the structure of one's work and feeling autonomy is supported by the relationships with others.

The relationships with other coaches within the organization were also important to the coaches in the current study. These relationships were important for both competence development and relatedness. The desire for mentoring and formal and informal networking among coaches is consistent with research (e.g., Inglis et al., 1996; Kilty, 2006; West et al., 2001). However, the inclusion of the concept of need satisfaction helps to explain why they are important. That is, coaches can learn and improve their coaching by working with other coaches and therefore their competence is developed. In addition, relatedness can also be fostered because the relationships enable coaches to feel that they are cared for and they are part of something: they belong.

The desire for connections with other coaches also parallels calls from researchers regarding the utility of communities of practice in the development of coaches (e.g., Culver \& Trudel, 2008). Consistent with Lave and Wenger's (1991) conceptualization, this research and discussion focuses on situated learning and how to foster coaches' learning. Although learning was not the only or explicit focus of the current study, communities of practice may be associated with satis- 
fying coaches' need for competence. For example, Culver and Trudel describe several studies where the facilitation of communities of practice among coaches demonstrated benefits to learning. In addition, one characteristic of becoming active participants in communities of practice involves mutual engagement which Culver and Trudel describe as being "about knowing where in the community to go for help and how to give help to others." (p.3). These actions are likely to influence coaches' sense of relatedness as well as competence. However, consistent with the findings of the current study, researchers have identified competition among coaches and a competitive reward structure as potential constraints to the development of communities of practice (Culver \& Trudel, 2008; Lemyre, Trudel, \& Durand-Bush, 2007).

\section{Future Directions}

The findings represent the experiences of a small group of women high performance coaches. In keeping with qualitative research it is not intended that these findings generalize to all coaches or indeed all women coaches. However, this research provides a starting point for those working with coaches to gain insight in the 'world of coaching' from the coaches' perspectives. Future research might extend this work to examine the experiences of coaches in other contexts and both men and women coaches to begin to further develop our understanding of the social context within which coaches operate. Through the use of quantitative and qualitative methods researchers might address questions such as the relative importance of each of the psychological needs to coaches' well-being, the relationship between need satisfaction and coaches' self-determined motivation and related outcomes of interest including well-being, retention and performance. Other researchers may wish to further explore the characteristics of the social context within sport organizations to add to our understanding of the actions of organizations that support or thwart coaches' psychological needs. Having developed such a body of knowledge researchers may look to examine the effectiveness of interventions designed to enhance the social context for coaches.

Interdisciplinary research that brings together psychological (Gould et al., 2002; Kilty, 2006), sociological (e.g., Knoppers, 1993; Sage, 1987; West et al., 2001), and management (e.g., Inglis et al., 1996; Shaw \& Hoeber, 2003) perspectives is likely to be useful to develop the bigger picture of the social context of coaching. Examining the extent to which environments such as communities of practice foster psychological needs would be useful in bringing together what might initially appear to be diverse concepts. Not only would this advance our understanding of coaches' experiences but also may lead to the development of research-based programs to redress the under-representation of women in coaching.

\section{Practical Implications}

In the current study an aspect of the coaches' social environment that was critical to the quality of their experiences was the relationships with other coaches and with key personnel in their organization. With regard to relationships with other coaches, the lack of mentors, specifically female mentors, and lack of access to 
networks reported by coaches in the current study have also been identified as a barrier to women high performance coaches' progression (Kilty, 2006; Shaw \& Hoeber, 2003; Theberge, 1993; West et al., 2001). Sport psychology practitioners are likely to be able to assist coaches to develop their networking skills, establish formal and informal networks, identify potential mentors, and establish effective mentor-mentee relationships. They may even facilitate the development of coaching communities of practice (Culver \& Trudel, 2006).

With regard to coaches' relationships with their organizations, sport psychology practitioners may assist coaches with considering their own psychological needs and well-being and with identifying actions that support (or thwart) their needs. Becoming familiar with the day-to-day work of coaches, the interactions with key personnel and the impact on coaches' needs will assist in this role. Organization leaders may need to consider how they can support coaches. This may involve developing an understanding of the difference between having autonomy and feeling that one's autonomy is supported. The findings of the current study suggest that demonstrating interest in coaches as people and in their work on a regular basis can be important for developing coaches' sense of relatedness within the organization and feeling that their autonomy was supported.

\section{Conclusion}

It has been argued that coaches should be considered as performers in their own right and their psychological needs considered. This study provides insight into the experiences of eight women high performance coaches with their sport organizations. All coaches were autonomous in their coaching practice. However, coaches in Organization A appeared to operate in a largely autonomy-supportive environment. In contrast, coaches in Organization B appeared to operate in a laissez-faire environment. The relationships among coaches and with key personnel in the sport organizations appeared to play a central role in the extent to which the environment was experienced as autonomy supportive.

\section{References}

Acosta, R.V., \& Carpenter, L.J. (2008). Women in intercollegiate sport. A longitudinal study - thirty-one year update. West Brookfield, MA: The project on women and social change of Smith College and Brooklyn College of the City University of New York.

Burgess, R.G. (1982). The unstructured interview as conversation. In R.G. Burgess (Ed.), Field research: A sourcebook and field manual (pp. 107-111). London: Allen \& Unwin.

Culver, D., \& Trudel, P. (2006). Cultivating coaches' communities of practice: Developing the potential for learning through interactions. In R.L. Jones (Ed.), The sports coach as educator: Re-conceptualising sports coaching (pp. 97-112). London: Routledge.

Culver, D., \& Trudel, P. (2008). Clarifying the concepts of communities of practice in sport. International Journal of Sports Science and Coaching, 3(1), 1-10.

Deci, E.L., \& Ryan, R.M. (1985). Intrinsic motivation and self-determination in human behavior. New York: Plenum. 
Doherty, A.J., \& Casey, C. (1996). The influence of sport socialization and family responsibilities on the underrepresentation of women interscholastic coaches. Avante, 2(3), $70-86$.

Erickson, K., Côté, J., \& Fraser-Thomas, J. (2007). Sport experiences, milestones, and educational activities associated with high-performance coaches' development. The Sport Psychologist, 21(3), 302-317.

Fontana, A., \& Frey, J.H. (2000). From structured questions to negotiated text. In N. K. Denzin \& Y. S. Lincoln (Eds.), Handbook of qualitative research (2 ed., pp. 645-672). Thousand Oaks, CA: Sage.

Gagné, M. (2003). The role of autonomy support and autonomy orientation in pro-social behavior engagement. Motivation and Emotion, 27(3), 199-223.

Gagné, M., \& Deci, E.L. (2005). Self-determination theory and work motivation. Journal of Organizational Behavior, 26, 331-362.

Giges, B., Petitpas, A.J., \& Vernacchia, R.A. (2004). Helping coaches meet their own needs: Challenges for the sport psychology consultant. The Sport Psychologist, 18, 430-444.

Gould, D., Greenleaf, C., Guinan, D., \& Chung, Y. (2002). A survey of U.S. Olympic coaches: Variables perceived to have influenced athlete performances and coach effectiveness. The Sport Psychologist, 16, 229-250.

Hollembeak, J., \& Amorose, A.J. (2005). Perceived coaching behaviors and college athletes' intrinsic motivation: A test of self-determination theory. Journal of Applied Sport Psychology, 17(1), 20-36.

Inglis, S., Danylchuck, K.E., \& Pastore, D. (1996). Understanding retention factors in coaching and athletic management positions. Journal of Sport Management, 10, 237-249.

Janesick, V.J. (2000). The choreography of qualitative research design: Minuets, improvisations, and crystallization. In N.K. Denzin \& Y.S. Lincoln (Eds.), Handbook of Qualitative Research (2nd ed., pp. 379-399). Thousand Oaks: Sage.

Jowett, S., \& Lavallee, D. (2007). Social psychology in sport. Champaign, IL: Human Kinetics.

Kilty, K. (2006). Women in coaching. The Sport Psychologist, 20, 222-234.

Knoppers, A. (1993). Gender ratio and social interaction among college coaches. Sociology of Sport Journal, 10, 256-269.

Lave, J., \& Wenger, E. (1991). Situated learning: Legitimate peripheral participation. Cambridge: Cambridge University Press.

Lemyre, F., Trudel, P., \& Durand-Bush, N. (2007). The learning experience of youth sport coaches. The Sport Psychologist, 21, 191-209.

Mageau, G.A., \& Vallerand, R.J. (2003). The coach-athlete relationship: A motivational model. Journal of Sports Sciences, 21, 883-904.

Marshall, D. (2001). Developing the next generation of women coaches. Canadian Journal for Women in Coaching Online, 1(4), 1-8.

Patton, M.Q. (2002). Qualitative Evaluation and Research Methods (2nd ed.). Newberry Park, CA: Sage.

Reinboth, M., Duda, J.L., \& Ntoumanis, N. (2004). Dimensions of coaching behavior, need satisfaction, and the psychological and physical welfare of young athletes. Motivation and Emotion, 29, 297-313.

Ryan, R.M., \& Deci, E.L. (2002). An overview of self-determination theory: An organismic-dialectical perspective. In E.L. Deci \& R.M. Ryan (Eds.), Handbook of selfdetermination research (pp. 3-33). New York: University of Rochester Press.

Sage, G.H. (1987). The social world of high school athletic coaches: Multiple role demands and their consequences. Sociology of Sport Journal, 4, 213-228. 
Shaw, S., \& Hoeber, L. (2003). 'A strong man is direct and a direct woman is a bitch': Analyzing discourses of masculinity and femininity and their impact on employment roles in sport organizations. Journal of Sport Management, 17(4), 347-376.

Silverman, D. (2001). Interpreting qualitative data. Methods for analyzing talk, text, and interaction (2nd ed.). London: Sage.

Theberge, N. (1993). The construction of gender in sport: Women, coaching, and the naturalization of difference. Social Problems, 40(3), 301-313.

West, A., Green, E., Brackenridge, C.H., \& Woodward, D. (2001). Leading the way: Women's experiences as sports coaches. Women in Management Review, 16(2), 85-92.

Womens Sports Foundation UK. (2007). The issues surrounding women and coaching. Available at www.wsf.org.uk Accessed 6 April, 2007.

NZ Olympic Committee. (2006). Profiles. Available at www.commonwealthgames.org.nz. Accessed 10 April, 2006.

NZ Olympic Committee. (2008). NZ Olympic Team to Beijing. Available at www.olympics.org.nz. Accessed 4 September, 2008. 